\title{
A INFLUÊNCIA DA ESTRATÉGIA COMPETITIVA DE POSICIONAMENTO DO PRODUTO NA ESTRUTURA DE GOVERNANÇA DA COMPRA DE EMBALAGENS DO SAG DO FRANGO DE CORTE
}

\section{THE INFLUENCE OF THE COMPETITIVE STRATEGY FOR POSITIONING THE PRODUCT ON THE GOVERNANCE STRUCTURE OF THE POULTRY PACKAGING SYSTEM}

\author{
Daniel Teixeira dos Santos Braz \\ Universidade Estadual de Maringá - PR \\ dantsb0@gmail.com \\ José Paulo de Souza \\ Universidade Estadual de Maringá - PR), \\ jpsouza@uem.br \\ Gaetano Martino \\ Università degli Studi di Perugia - Itália) \\ gaetano.martino@unipg.it
}

Submissão: $25 / 05 / 2021$

Aprovação:26/08/2021

\begin{abstract}
RESUMO
Este artigo trata da influência do posicionamento estratégico na estrutura de governança nas transações entre fornecedores de embalagens e processadores de produtos cárneos, no Sistema Agroindustrial (SAG) de aves. Tem o objetivo de compreender como a busca de eficiência na transação com o segmento fornecedor de embalagem é influenciado pelo posicionamento estratégico do segmento processador, no SAG de frango de corte. As principais teorias utilizadas são: ECT e Estratégia Competitiva. Paralelamente são utilizados aspectos da teoria de posicionamento estratégico competitivo. Metodologicamente o estudo tem natureza qualitativa, são realizadas entrevistas com roteiros semiestruturados, onde se faz uma análise de conteúdo com categorias concebidas previamente pela teoria. Os principais resultados são os seguintes: Quando a estratégia competitiva do processador é orientada para a diferenciação, a transação estudada exige a estrutura híbrida, mais próxima da hierarquia, para se manter eficiente. Da mesma forma, quando a estratégia competitiva é orientada para custos ou enfoque, essa influência deve direcionar a estrutura de governança para a forma híbrida que tende ao mercado.
\end{abstract}

Palavras-chave: Estrutura de governança. Nova Economia Institucional. Posicionamento estratégico. 


\section{ABSTRACT}

This article deals with the influence of strategic positioning on the governance structure in transactions between packaging suppliers and meat product processors, in the poultry Agroindustrial System (AGS). It aims to understand how the search for efficiency in the transaction with the packaging supplier segment is influenced by the strategic positioning of the processor segment, in the broiler chicken AGS. The main theories used are: TCE and Competitive Strategy. In parallel, aspects of the competitive strategic positioning theory are used. Methodologically the study has a qualitative nature, interviews are conducted with semi-structured scripts, where a content analysis is made with categories previously conceived by the theory. The main results are as follows: When the competitive strategy of the processor is oriented towards differentiation, the studied transaction requires the hybrid structure, closer to the hierarchy, to remain efficient. Likewise, when the competitive strategy is oriented towards costs or focus, this influence should direct the governance structure towards the hybrid form that tends to the market.

Keywords: Governance structure. New Institutional Economics. Strategic positioning.

\section{INTRODUÇÃO}

O problema a ser pesquisado neste estudo é o de determinar qual a relação entre o posicionamento estratégico da empresa e a sua eficiência no processo de compra de insumos. O contexto em que este problema será estudado é o do SAG de frango de corte e, portanto, o objetivo deste estudo é de compreender como a busca de eficiência na transação com o segmento fornecedor de embalagem é influenciado pelo posicionamento estratégico do segmento processador, no SAG de frango de corte. Com isso, o artigo buscará esse objetivo, através de uma pesquisa qualitativa, com dados primários coletados através de entrevistas com roteiro semiestruturado e tratado através de análise de conteúdo.

O contexto do SAG de frango de corte no Brasil é caracterizado por uma organização estrutural e econômica da cadeia produtiva que aumentou significativamente de 2000 a 2015 (IBGE, 2017; ABPA 2018; WAKER e NÄÄS 2018). Neste ambiente de alta competitividade, Raimundo e Batalha (2015) apresentam um elemento, que no Sistema Agroindustrial (SAG) da carne avícola é fundamental: a embalagem. Para os autores essa é uma das tecnologias mais estratégicas a serem incorporadas, pois o produto é perecível e não possui um diferencial aparente, se não for devidamente informado ao consumidor por intermédio das embalagens. Essa condição de interdependência define que mecanismos de coordenação devem estar presentes de forma a alinhar os objetivos estratégicos e produtivos, não só na cadeia produtiva, mas também nas relações laterais, com o setor de embalagens (RAIMUNDO; BATALHA 2015).

Neste contexto, o problema identificado neste estudo se justifica pela necessidade de entender a busca pela eficiência na compra de embalagens, enquanto a indústria busca paralelamente manter um posicionamento estratégico competitivo no mercado de frango de corte. Sendo assim, o enfoque principal a ser destacado ao longo deste estudo é a transação de aquisição da embalagem. Por isso, devido aos variados atributos que influenciam em uma transação e à complexidade institucional e informacional que envolvem o produto embalagem, adota-se a perspectiva que mais abrange estes aspectos, a ECT, conforme Ketokivi e Mahoney (2020), Mugwagwa et al. (2020), Yuan et al. (2020). Adicionalmente, estudos com essa natureza de problema, tratando da interação entre estratégia competitiva e busca pela eficiência, através da ECT, já foram explorados por Foss e Foss (2004), Cunha et 
al. (2015), Ghozzi (2016), Caleman et al. (2017), Zylbersztajn (2018), Augusto et al. (2018; 2019) e Asmussen et al. (2020). Entretanto, a inclusão do segmento fornecedor de embalagem pela visão do processador, particularmente nesse sistema agroindustrial, carece de mais estudos.

Por fim, essa forte relação envolvendo uma transação entre o segmento processador e o segmento fornecedor de embalagens motivou o presente estudo. Por fim, tem-se que este estudo é estruturado com introdução, fundamentação teórica, procedimentos metodológicos, apresentação e análise de resultados e, por fim, as considerações finais e referências.

\section{FUNDAMENTAÇÃO TEÓRICA}

As categorias levantadas ao final desta fundamentação serão as ferramentas teóricas utilizadas para o atingimento dos objetivos deste estudo, portanto, serão as lentes sob as quais este estudo vai compreender a transação entre o SAG avícola e os fornecedores de embalagem, e a influência recebida pelo posicionamento estratégico.

\subsection{ECONOMIA DOS CUSTOS DE TRANSAÇÃO E POSICIONAMENTO ESTRATÉGICO}

Os estudos em Economia dos Custos de Transação e sua abordagem detalhada sobre os atributos da transação e a adaptação da estrutura de governança são indicados para compreender transações envolvidas em ambientes institucionais complexos e são de grande contribuição para o contexto do gerenciamento de cadeia de suprimentos, pois fornecem uma visão heterodoxa para a área (KETOKIVI; MAHONEY, 2020; MUGWAGWA et al., 2020; YUAN et al., 2020).

Conforme Williamson (1991), a Economia dos Custos de Transação (ECT) se preocupa com as estruturas de governança, pois tem, como pressuposto, que os custos de transação são positivos, ou seja, que existem custos para proteger e capturar direitos de propriedade. Nessa orientação, a definição de custos de transação para o autor envolve: Custos de planejar, negociar, construir, mensurar, fiscalizar e adaptar contratos, quando a sua execução é afetada por falhas, erros, omissões e alterações inesperadas. No entanto, o caráter peculiar da teoria vai além da preocupação com estruturas de governança, pois na abordagem da Economia dos Custos de Transação existem os pressupostos comportamentais, que são caracterizados pela racionalidade limitada e oportunismo (WILLIAMSON, 1991). Além dos aspectos comportamentais, a ECT analisa os atributos da transação como especificidade de ativos, incerteza e frequência (idem, ibidem). A especificidade dos ativos, entretanto, é a variável-chave do modelo.

As estruturas de governança podem ser: mercado, híbrido e hierarquia. Zylbersztajn (2018) oferece uma explicação para a ocorrência das formas de governança que atuam conforme os níveis de especificidade dos ativos e do atributo incerteza. No entanto, faz-se necessário considerar uma incerteza adicional levantada por Crook et al. (2013), a incerteza de volume e tecnológica que, apesar de ser causada pelo ambiente também, apresenta uma tendência para governança híbrida, contrariamente ao que se determinam as outras incertezas.

Quanto à relação entre a estrutura de governança e o posicionamento estratégico, Farina (1999) afirma que a configuração de um determinado sistema depende das relações, o que vai de encontro com o argumento principal de Jank, Farina e Galan (1999), que reafirmam a necessidade de entender a adequação das estruturas de governança, relacionandose com as estratégias individuais competitivas, pois as mesmas podem ser obstruídas por 
"gargalos de coordenação vertical ou de logística" e, a partir disso, faz-se necessário analisar a coordenação em uma perspectiva de eficiência. Esse argumento é ratificado por Ketokivi e Mahoney (2020).

Nessa mesma linha, Foss e Foss (2004), em sua abordagem, apresenta a necessidade de considerar a estratégia competitiva alinhada com mecanismos de proteção de valor, como, por exemplo, a estrutura de governança. Isto também é ratificado por Asmussen et al. (2020), que tratam especificamente deste assunto, a relação entre competição e eficiência.

Estes argumentos são incorporados na abordagem de Saes (2009), ratificada posteriormente por Asmussen et al. (2020), que apresentam o posicionamento das empresas, com relação ao ambiente que estão inseridas, como algo fundamental para configurar as estruturas de governança. Saes (2009) afirma que a ECT fornece suporte para a empresa estabelecer sua posição estratégica em relação ao mercado (mercado, contratos e hierarquia), dependendo dos custos da transação analisada. Ao considerar a proposta de Porter (1980) de que os posicionamentos estratégicos são a procura por uma posição competitiva favorável em uma indústria, Saes (2009) desenvolveu em seu estudo uma forma de adequar estratégia de posicionamento aos estudos de ECT e SAG.

Os posicionamentos estratégicos de Porter (1980) adaptados por Saes (2009) são: Liderança em custo (manter custos abaixo do nível de custos da concorrência); Diferenciação (tornar o produto único, ou diferente, acima do nível de preços da concorrência); Foco (criar dedicação específica a um determinado grupo de clientes, produtos, canal de distribuição ou região). Dessa forma, para melhor operacionalizar a pesquisa, ao desdobrar as necessidades dos objetivos de pesquisa em categorias, as definições constitutivas e operacionais foram elaboradas.

As definições se encontram na seguinte configuração:

\section{a) Posicionamento Estratégico;}

Definição constitutiva: Os posicionamentos estratégicos são a procura por uma posição competitiva favorável em uma indústria (PORTER, 1980). Eles são: posicionamento de liderança por custos, diferenciação (por marca, qualidade, etc.) e foco (em um segmento de clientes ou canal específico).

Definição operacional: $\mathrm{O}$ posicionamento é caracterizado mediante ações gerais do processador, seja em buscar uma relação menos custosa e sem diferencial aparente no produto, ou ações a fim de manter uma marca com padrão alto de qualidade, ou ações focadas para determinado aspecto do produto ou da região (SAES, 2009).

\section{b) Atributo de transação: Especificidade de ativos;}

Definição constitutiva: Especificidade de ativos é caracterizada como perda do valor dos ativos envolvidos em determinada transação e elas podem ser classificadas em: locacional, de ativos físicos, de ativos humanos, ativos dedicados, especificidade de marca e especificidade temporal (WILLIAMSON, 1985).

Definição operacional: Neste estudo, especificidade de ativos é caracterizada através da identificação de requisitos específicos de produto para realizar a transação da embalagem ou as condições específicas que são estabelecidas para a negociação. Sendo assim, para se configurar como especificidade do ativo, é necessário que tais condições façam com que a realização da transação fique mais difícil, ou mais demorada, ou que exija um esforço considerável por, pelo menos, uma das partes para que a transação seja efetuada.

\section{c) Atributo de transação: Incerteza;}

Definição constitutiva: A incerteza pode ser ambiental (possibilidades de mudança nas condições de mercado e climáticas) e comportamental (possibilidade de comportamento oportunista acontecer), sendo que, dessa forma, é diretamente proporcional à verticalização (WILLIAMSON, 1985). Adicionalmente, segundo Crook et al. (2013), a incerteza também pode indicar uma estrutura híbrida, se for relacionada à variação de volume ou à mudança 
tecnológica, pois, apesar dessa incerteza derivar do ambiente como as outras, possui a especificidade de ser melhor controlada através dos contratos.

Definição operacional: Neste trabalho, incerteza ambiental será considerada através das situações de quebra contratual e de mudanças de requisitos repentinas. As mudanças podem ser em volume, tecnologia, preços ou outros requisitos. O foco é dado às mudanças que desfavoreçam uma das partes devido a condições de mercado como crise, mudança de estratégia de posicionamento do agente, podendo levar à verticalização (preços, requisitos, mercado, outros) ou à estrutura híbrida (volume, tecnologia), dependendo de qual aspecto é mais afetado pela incerteza. Já a incerteza comportamental se dará através de quebra contratual e mudanças nos requisitos contratuais, que desfavoreçam uma das partes devido a erros na elaboração do contrato ou devido à tentativa de uma das partes de se favorecer indevidamente na transação, levando a uma verticalização das estruturas.

d) Atributo de transação: Frequência;

Definição constitutiva: Número de vezes que agentes transacionam, capaz de gerar reputação ou espaço para oportunismo (FARINA, 1999).

Definição operacional: No presente estudo, a frequência será considerada através da consideração do tempo em que os mesmos agentes efetivam transações entre si.

\section{e) Estrutura de governança;}

Definição constitutiva: Estrutura de governança é o mecanismo de coordenação que determina a maneira que as transações são configuradas, caracterizando-se em três formas: via mercado, híbrido e integração vertical (WILLIAMSON, 1985).

Definição operacional: Neste estudo, para a estrutura de governança será considerada a maneira como se organizam a relação comercial entre processador de aves e fornecedor de embalagem, podendo ser via mercado, via contratação, ou via integração vertical.

\section{PROCEDIMENTOS METODOLÓGICOS}

O estudo é de natureza qualitativa e de caráter descritivo. A pesquisa qualitativa é caracterizada como descritiva e comparativa quando procura descrever com exatidão os fatos e fenômenos de determinada realidade e depois compará-los. Para isso é necessário um método adequado e explícito de análise, a fim de garantir rigor e confiabilidade na pesquisa (AUGUSTO et al. 2013). Portanto, a pesquisa alinha-se a esses pressupostos, já que busca descrever fatos da realidade e compará-los, através da lógica da Economia dos Custos de Transação e do seu construto de Estrutura de Governança.

O objeto de estudo foi o SAG avícola no estado do Paraná, por conveniência de proximidade, limitação de custos e porque é um dos estados mais representativos do país, segundo ABPA (2018), na produção de frango de corte. Segundo EMBRAPA (2018) e IBGE (2017), as regiões Norte, Oeste, Sudeste e Noroeste do Paraná possuem alta concentração de processadores de frango de corte e, por isso, foi onde as entrevistas se realizaram.

A análise dos dados se deu por análise de conteúdo de Bardin (2016). Neste estudo optou-se pela análise de conteúdo direcionada. Com uma análise de conteúdo direcionada, o pesquisador usa categorias teóricas pré-concebidas antes de começar a análise (HSIEH; SHANNON, 2005). Portanto, a transcrição da entrevista para este tipo de análise é desnaturalizada devido à necessidade de encaixar o conteúdo em categorias sistematizadas e pré-concebidas (NASCIMENTO; STEINBRUCH, 2019).

Nessa orientação, através da análise de conteúdo, segundo as proposições de Bardin (2016), buscou-se a categorização para decodificar informações, levando o pesquisador a 
formar um sistema de categorias de análise. As categorias, portanto, perpassaram os conceitos apresentados na seção de fundamentação teórica - estruturas de governança, especificidade, frequência, incerteza, estratégias de liderança em custo, diferenciação e foco. Quanto aos entrevistados, buscou-se obter informações de empresas de diferentes tamanhos, mas com tempo de mercado de elevada duração, de forma a se obter consistência e identificar aspectos de variação ao longo do tempo.

Com o objetivo de compreender a configuração do objeto de estudo, a quantidade de entrevistas foi definida pelo nível de saturação de conteúdo das informações presentes em campo e pela conveniência de acesso. Portanto, foram ouvidas quatro empresas cooperativas e três empresas privadas, localizadas nas regiões indicadas, o que permitiu atingir o nível de saturação desejada. O levantamento de dados foi realizado por intermédio da interrogação dos envolvidos por meio de entrevistas semiestruturadas. A pesquisa caracteriza corte seccional. Adicionalmente, para a realização do roteiro de perguntas semiestruturado deste estudo, a fim de diferenciar posicionamentos dos produtos e atributos da transação, decidiu-se dividir as principais características da embalagem e torná-las uma espécie de subcategorias de análise, a fim de facilitar a comunicação com os entrevistados e melhor averiguar aspectos da transação da embalagem.

Por fim, em estudos qualitativos, a formulação de questões de pesquisa possui grande importância para direcionar e delimitar o trabalho a ser desenvolvido. Skarbek (2020) afirma que é necessário que o pesquisador, em busca de evidências qualitativas, tenha clareza na formulação da questão de pesquisa, a fim de minimizar o risco de não conseguir interpretar os dados. Sendo assim, as questões elaboradas para o roteiro de pesquisa devem refletir as definições constitutivas e operacionais e, por sua vez, são desdobramentos dos objetivos específicos, que orientaram e direcionaram o presente estudo, de forma clara e objetiva, conforme apontou Skarbek (2020). Seguindo esta linha de raciocínio, foi construído o roteiro de perguntas, deste trabalho.

A divisão e a relação entre as divisões do roteiro identificam as características do produtor, as condições de mercado e o posicionamento estratégico como influenciador na escolha de estrutura de governança da compra de embalagens. Assim, o primeiro grupo lida com as características da empresa e estratégias de posicionamento do produto; o segundo lida com as características da embalagem e a identificação da importância de cada atributo dela para a transação; e o terceiro é a preocupação com a análise dos atributos de transação e estrutura de governança.

No primeiro momento, com relação à busca pela definição de posicionamento estratégico, utiliza-se como critério principal as características específicas da embalagem estudada e se possui muita diferenciação de uma embalagem comum, a fim de entender como as empresas diferenciam seus produtos por intermédio da embalagem.

Já no segundo momento do questionário, para identificar a importância de cada atributo para a transação, segue-se a indicação de Barão (2011) e utilizam-se a seguintes categorias de atributo da embalagem: Rótulo, forma estrutural, design gráfico, material, atendimento de requisitos e equipamentos.

Por fim, no terceiro momento, analisam-se as especificidades e atributos de transação, o que determinará a escolha de estrutura de governança para coordenar essa transação, onde identifica-se a possibilidade de a estrutura real estar inadequada e, portanto, a partir desta análise será possível propor uma estrutura ideal de governança que consiga agregar eficiência e competitividade.

Para entender a análise de escolha de estrutura de governança real e ideal, que determina como a estrutura de governança é configurada, serão analisados, especificamente, 
os seguintes pontos: dificuldades em configurar, negociar e renegociar contratos, características de embalagem, atributos da transação,

Essas relações entre as questões e as preposições orientaram a coleta dos dados e informações para o estudo, bem como sua organização. Esse conjunto foi analisado pela técnica de análise de conteúdo, conforme já apresentado nesta seção. A análise de conteúdo, segundo Bardin (1979), traz a categorização como um meio para decodificar as informações adquiridas através da entrevista qualitativa, levando o pesquisador a formar um sistema de categorias de análise.

O sistema de categoria de análise é composto pelo desenho de pesquisa, conforme Figura 1, e detalhado nas relações entre posposições e entre questões. Com isso é possível realizar a separação da incerteza no conteúdo, garantindo confiabilidade e coerência. Adicionalmente, a sistematização das categorias favorece a função heurística e administração de provas necessárias para a operacionalização das teorias utilizadas neste estudo.

Figura 1 - Desenho de pesquisa.

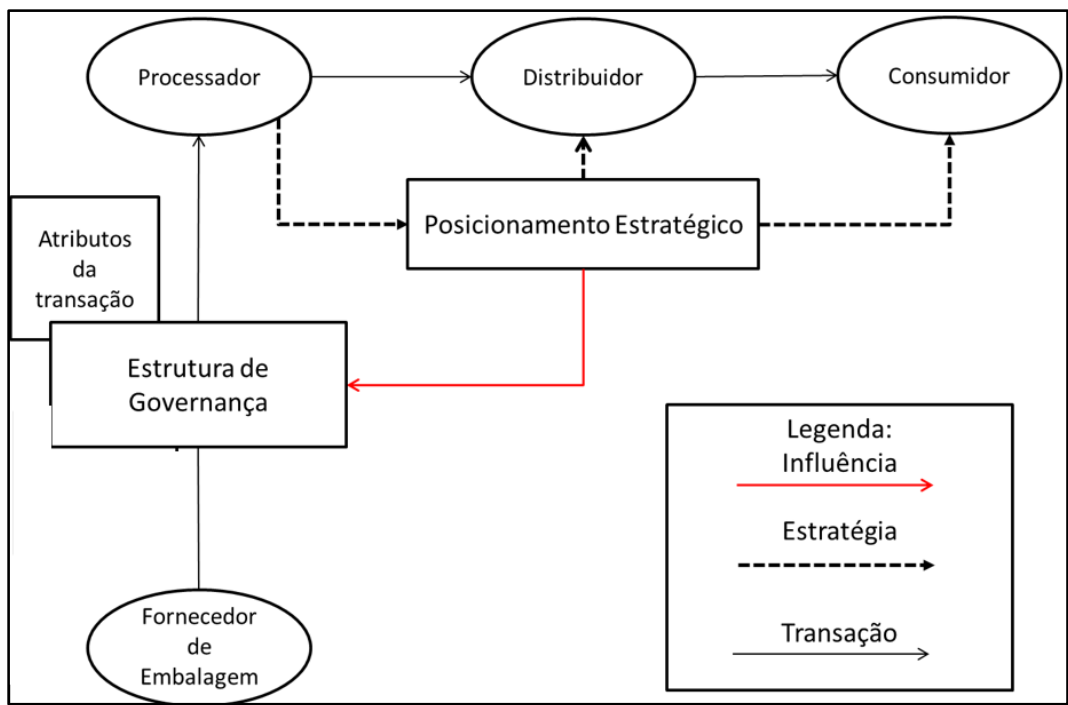

Fonte: Elaboração do autor

Por fim, em estudos qualitativos, a formulação de questões de pesquisa possui grande importância para direcionar e delimitar o trabalho a ser desenvolvido. Seguindo esta linha de raciocínio, foi construído o roteiro semiestruturado de perguntas, deste trabalho.

A divisão e a relação entre as divisões do roteiro identificam as características do produtor, as condições de mercado e o posicionamento estratégico como influenciador na escolha de estrutura de governança da compra de embalagens. Assim, o primeiro grupo lida com as características, o segundo, com as estratégias e o terceiro, com a preocupação com a análise da estrutura de governança.

As perguntas são divididas para esses três grupos e cada um deles tem objetivos diferentes. A primeira parte considera as características da empresa, do produto, do mercado em geral e do posicionamento estratégico. Isso significa que essa parte vai entender a história, as atividades atuais, o tamanho e o mercado em que a empresa está envolvida. Nessa, identifica-se, também, como a empresa alcança diferenciação através de tecnologia ou marca, considerando as seguintes características das embalagens, tais como: Rótulo, forma estrutural, design gráfico, material, atendimento de requisitos e equipamentos. 
O segundo grupo trata do posicionamento estratégico, no qual é possível visualizar as características específicas do tipo de diferenciação e as partes que influenciarão a estrutura de governança. Para entender como as empresas diferenciam seus produtos por intermédio da embalagem, devemos saber como o posicionamento estratégico de toda a empresa se encaixa na decisão de compra do pacote.

Dependendo da característica do produto e da embalagem, haverá um posicionamento diferente no mercado. Portanto, as diferenças de embalagem são importantes para o posicionamento estratégico, pois fornecerão informações de marca, qualidade e segurança alimentar por meio de aspectos visuais, como rótulo, design gráfico, forma estrutural, material, equipamento e montagem nos requisitos específicos de embalagem.

O investimento é algo importante para fazer as análises, pois existe a possibilidade de se tornar específico, e algumas das características que podem criar especificidade na transação podem influenciar a estratégia de agregar valor, através de tecnologia ou marca. Essa ideia pode ser representada através da Figura 2.

Figura 2 - Relação das variáveis no segundo bloco de perguntas.

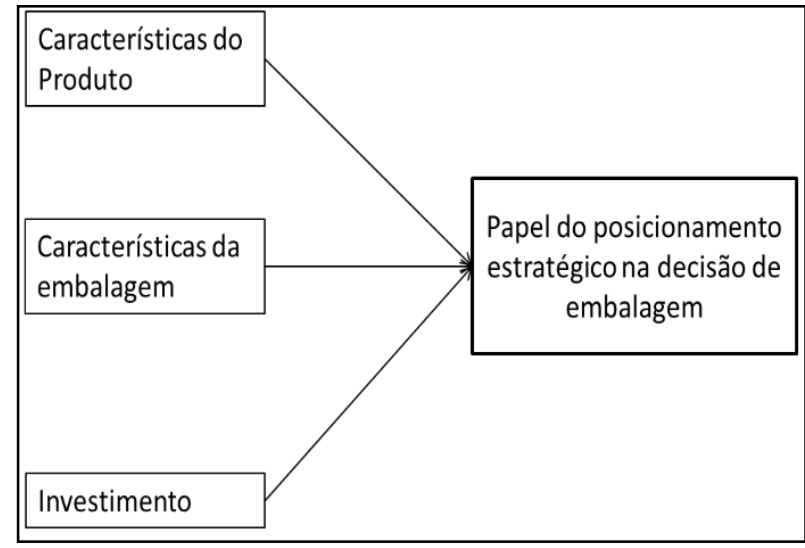

Fonte: Elaboração do autor.

A terceira parte é também a análise final que determinará a escolha organizacional e lida com a análise de adaptação da estrutura de governança. Para entender a escolha organizacional que determina como a estrutura de governança é configurada, serão analisados, especificamente, os seguintes pontos: dificuldades em configurar, negociar e renegociar contratos, características de embalagem, atributos da transação e questões de mensuração. Essa ideia pode ser representada pela Figura 3.

Figura 3 - Relação das variáveis no terceiro bloco de perguntas.

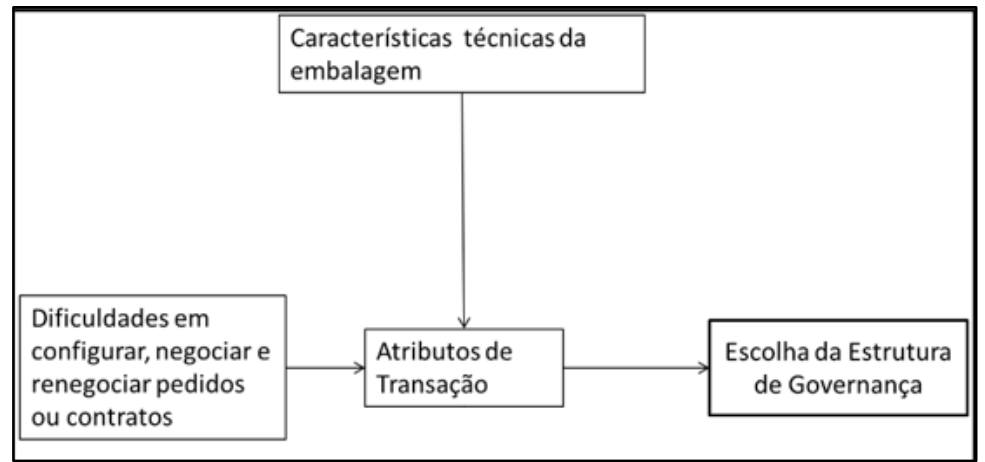

Fonte: Elaboração do autor. 
Essas relações entre as questões e as preposições orientaram a coleta dos dados e informações para o estudo, bem como sua organização. Esse conjunto foi analisado pela técnica de análise de conteúdo, conforme já apresentado nesta seção.

\section{APRESENTAÇÃO E ANÁLISE DOS RESULTADOS}

A partir das evidências qualitativas, consolidadas como evidências científicas por Skarbek (2020), coletadas nas entrevistas semiestruturadas, foi feita uma análise de conteúdo, proveniente dos estudos de Bardin (2016), direcionada a partir das categorias teóricas desta revisão de literatura. Esta análise de conteúdo é feita consolidando a saturação das falas de todos os entrevistados, encaixando o conteúdo de suas colocações nas categorias do estudo. No Quadro 1 é possível discriminar as características de cada entrevistado.

Quadro 1 - Entrevistados e suas características.

\begin{tabular}{|c|c|c|c|c|c|c|c|}
\hline Entrevistados: & $\begin{array}{c}\text { Cooperativa } \\
1\end{array}$ & $\begin{array}{c}\text { Cooperativa } \\
2\end{array}$ & $\begin{array}{c}\text { Cooperativa } \\
3\end{array}$ & $\begin{array}{c}\text { Cooperativa } \\
4\end{array}$ & $\begin{array}{c}\text { Empresa } \\
\text { privada } \\
1 \\
\end{array}$ & $\begin{array}{c}\text { Empresa } \\
\text { privada } \\
2 \\
\end{array}$ & $\begin{array}{c}\text { Empresa } \\
\text { privada } \\
\mathbf{3} \\
\end{array}$ \\
\hline $\begin{array}{c}\text { Cargo do } \\
\text { entrevistado: }\end{array}$ & $\begin{array}{l}\text { Gerente de } \\
\text { P\&D }\end{array}$ & Compras & $\begin{array}{l}\text { Gestor de } \\
\text { negócios }\end{array}$ & $\begin{array}{c}\text { P\&D e } \\
\text { Compras }\end{array}$ & Compras & Compras & Compras \\
\hline $\begin{array}{c}\text { Tamanho da } \\
\text { empresa: }\end{array}$ & Grande & Média & Grande & Grande & Média & Pequeno & Pequeno \\
\hline $\begin{array}{l}\text { Quantidade de } \\
\text { embalagem } \\
\text { comprada: } \\
\text { (mensalmente e } \\
\text { aproximadamen } \\
\text { te) }\end{array}$ & 300 t /mês & $\begin{array}{l}30 \text { a } 40 \mathrm{t} \\
\text { /mês }\end{array}$ & 80 t /mês & 130 t /mês & $\begin{array}{l}262 \mathrm{t} \\
/ \mathrm{mês}\end{array}$ & $40 \mathrm{t} / \mathrm{mês}$ & $40 \mathrm{t} / \mathrm{mês}$ \\
\hline $\begin{array}{l}\text { Material da } \\
\text { embalagem: }\end{array}$ & $\begin{array}{c}\text { Plástico(PEB } \\
\text { D/PETt+PE/N } \\
\text { YLON/PEAD } \\
\text { )/Papelão }\end{array}$ & $\begin{array}{l}\text { Plástico(PEB } \\
\text { D)/Papelão }\end{array}$ & $\begin{array}{c}\text { Plástico(PE } \\
\text { BD/PETt+P } \\
\text { E/NYLON/P } \\
\text { EAD)/Papel/ } \\
\text { Papelão }\end{array}$ & $\begin{array}{l}\text { Plástico(PEB } \\
\text { D/PETt+PE/ } \\
\text { NYLON/PEA } \\
\text { D)/Papel/Pap } \\
\text { elão }\end{array}$ & $\begin{array}{l}\text { Plástico( } \\
\text { PEBD)/P } \\
\text { apelão }\end{array}$ & $\begin{array}{l}\text { Plástico( } \\
\text { PEAD)/ } \\
\text { Papelão }\end{array}$ & $\begin{array}{c}\text { Plástico( } \\
\text { PEBD/ } \\
\text { PEAD) } \\
\text { /Papelão }\end{array}$ \\
\hline
\end{tabular}

Fonte: Elaboração do autor.

Com isso, é possível se consolidar as informações sobre os posicionamentos estratégicos das empresas e os reflexos desse posicionamento na sua negociação de embalagens e, consequentemente, nos atributos da transação e estrutura de governança.

\subsection{ESTRATÉGIA DO POSICIONAMENTO DE PRODUTO}

$\mathrm{Na}$ análise de conteúdo foi possível observar também que a maioria dos entrevistados informou que a empresa em que atuam é posicionada estrategicamente em Liderança por custos. A embalagem, por unanimidade nesse posicionamento, faz com que o produto se comunique, principalmente através da comunicação visual. Seja por intermédio de uma boa impressão e boa aparência, cumprindo requisitos básicos, ou a partir de artes atrativas e chamativas desenvolvidas com pesquisa de tendência e de mercado.

Todos os entrevistados descrevem seu histórico de mudanças tecnológicas e expansão, baseados nos marcos de autorização institucional para expansão, seja atendendo padrões do SIF para vender para todo o país, seja atendendo padrões internacionais de qualidade e segurança alimentar, para exportação. Tais padrões pré-estabelecidos para todos se tornam custos que as organizações não podem reduzir. Isso inclui custos com qualidade, ração, produção, dentre outros. Sendo assim, nas organizações posicionadas por custos, há uma necessidade em reduzir custos nos insumos da cadeia de apoio e isso inclui a embalagem. Portanto, na visão dos entrevistados, esse posicionamento influencia diretamente como a organização compra embalagem. 
A forma da organização que se posiciona por custos, conforme as entrevistas, mostrar um diferencial em sua embalagem é pelo design gráfico, que é a forma menos custosa para fazer isso. A resposta obtida do representante da Empresa privada 1 ratifica a opinião das empresas posicionadas estrategicamente por custos sobre se diferenciar através do design gráfico "Uma embalagem bonita, com boas artes gráficas, material e cores, sempre chama mais atenção do que uma embalagem comum e influencia diretamente na decisão de compra do consumidor".

Além disso, por unanimidade, as organizações que se posicionam por custos não fazem investimentos em $\mathrm{P} \& \mathrm{D}$ e em novas tecnologias; apenas se adaptam às mudanças obrigatórias e investem em marketing. Isso, consequentemente, conforme afirmam, faz com que seu produto tenha um preço mais competitivo no mercado. A Empresa privada 1, em sua resposta sobre mudanças e investimentos em embalagem, ratifica a opinião da maioria: "A maioria das mudanças é para uma questão mercadológica de design gráfico que não exige muito investimento em novas tecnologias".

Uma outra característica das organizações pertencentes a esse posicionamento, observada através da análise, é a forma de lidar na hora da homologação de fornecedores e negociação. Conforme os entrevistados, a homologação é mais "branda", ou seja, como normalmente a maioria das empresas desse posicionamento não tem muita variedade de produtos, vendendo apenas cortes e produto inteiro, suas embalagens, por consequência, são mais simples. Sendo assim, podem homologar a maioria dos fornecedores para todos os produtos. Com essa estratégia eles não dependem apenas de um fornecedor e podem sempre cotar os seus produtos quando acham que o preço não está de acordo com sua estratégia. Tal estratégia, apesar de trazer benefícios em custo, não permite ter certificações de qualidade mais rigorosas, pois exigem uma auditoria e consequente homologação de fornecedor mais rigorosa.

A resposta da Cooperativa 2 sobre a negociação da embalagem reforça a opinião da maioria das empresas posicionadas por custos: "Faz cotação nos fornecedores testados e aprovados para todos os produtos. Busca o menor preço e com a qualidade desejada. Utiliza termo de negociação e a negociação ocorre sempre e normalmente não ocorrem problemas". No entanto, dentro desse posicionamento, com relação à forma de negociação, existem exceções que ocorrem quando a empresa possui elevada variedade de produtos. Isso ocorre nas Cooperativas 3 e 4, identificadas neste estudo, que, apesar de se posicionarem por custos, buscam uma variedade maior de produtos e, portanto, acabam negociando de forma diferente os produtos com mais diferenciação.

As Cooperativas 3 e 4 são, portanto, uma exceção no posicionamento por custos devido a sua variedade de produtos, oferecendo produtos em natureza (inteiro, cortes, congelados), produtos temperados, produtos industrializados (empanados e linguiças). O fato de oferecer produtos industrializados, principalmente exige embalagens específicas e fornecedores específicos. No entanto, fora isso, mantêm as práticas de posicionamento por custos, inclusive a da cotação de preços e consideram que os contratos temporários podendo ser rompidos a qualquer momento, como uma relação de mercado.

Outra exceção é a Cooperativa 1, que foi identificada pela busca de posicionamento por diferenciação. Essa empresa oferece produtos processados e prontos para consumo, além dos produtos como cortes e cortes congelados. No entanto, não oferecem o produto inteiro, que seria a "commodity", em se tratando de carne de aves. Além disso, a Cooperativa 1 é a que mais possui certificações, tecnologias e ideias diferentes para destacar seu produto, como certificações de qualidade a mais do que as outras e certificações em sustentabilidade. Isso faz com que a homologação dos fornecedores desta empresa seja muito mais rígida e a relação com eles muito mais próxima como a de "parceiros", segundo o entrevistado da Cooperativa 1. 
Essa diferenciação buscada pela Cooperativa 1 tem como principal característica, segundo os entrevistados, o alto investimento dedicado às certificações e tecnologias.

Já no caso do outro posicionamento de custos, é levado em consideração apenas o fato de não ter erros nos requisitos básicos, exigidos nas fichas técnicas. Conforme os entrevistados, se os erros não forem tão graves, as embalagens serão levadas adiante e os custos serão o principal aspecto da negociação. Sendo assim, para a organização que busca diferenciação, ou há um investimento em específico no setor de $\mathrm{P} \& \mathrm{D}$ ou nos processos relacionados a esse setor. Já em outros casos, há na maioria uma preocupação em investir no marketing e maquinário, ou manutenção, mas sem uma relevância significativa comparada ao investimento em P\&D.

O posicionamento por foco em um nicho específico é também uma exceção, como o posicionamento por diferenciação que possui apenas uma empresa, dentro deste estudo. Esse posicionamento se caracteriza devido à estratégia da organização estar focada em cumprir requisitos específicos a um determinado nicho. A Empresa privada 2 é a empresa que está enquadrada nesta exceção, conforme apresenta na seguinte afirmação: "atua só no mercado interno, segue uma clientela que fideliza, preza pela confiança com o cliente". Sendo assim, observa-se que a empresa apenas vende para o Brasil e foca no distribuidor/consumidor Brasileiro.

Segundo a Empresa privada 2, ela busca se adaptar às preferências do consumidor, que são: "embalagens menores para porções menores ou misturas de corte". Para a adaptação ao nicho, o entrevistado afirma que a empresa buscou embalagens mais justas, com o material de embalagem diferente da maioria: polietileno de alta densidade. Portanto, a Empresa privada 2, além de buscar conquistar a confiança desse consumidor/distribuidor através dos seus materiais e arranjos de produtos diferentes, conforme a demanda dos mesmos, utiliza também sua forma de negociação para atender a demanda específica. Por fim, são elencadas as principais características dos posicionamentos que afetam a compra de embalagem, segundo a análise.

Quadro 2 - Síntese das características dos posicionamentos.

\begin{tabular}{|c|l|}
\hline Posicionamento Estratégico & \multicolumn{1}{c|}{ Efeito na compra de embalagem } \\
\hline Diferenciação & $\begin{array}{l}\text { Mais investimentos específicos em qualidade, } \\
\text { funcionalidade e marca }\end{array}$ \\
\hline Custos/Foco & $\begin{array}{l}\text { Buscar liderança através da redução de custos } \\
\text { e investimentos/ Buscar determinado } \\
\text { mercado em específico; }\end{array}$ \\
\hline
\end{tabular}

Fonte: Elaboração do autor.

A partir desta primeira parte da análise em que se verifica o posicionamento e as dificuldades e diferenças na negociação das embalagens, faz-se necessário verificar a segunda parte da análise, que vai analisar as características da embalagem a partir da tomada de decisão sobre o posicionamento estratégico.

\subsection{ATRIBUTOS DE TRANSAÇÃO E ESTRUTURA DE GOVERNANÇA}

O posicionamento estratégico dos produtos, as características da embalagem e seus atributos de mensuração influenciam diretamente nos atributos da transação da embalagem. Dessa forma, a seguir serão analisadas as características dos atributos influenciadas por estas variáveis.

Conforme visto em entrevistas, é unanimidade entre os processadores que o prazo de entrega é um problema de maior importância nessa transação, pois afeta aspectos internos e 
externos, como: tempo de produção, estoque parado, mudança no "mix" de produção, vendas, atendimento ao mercado. $\mathrm{O}$ fato de não saberem o volume a ser comprado faz com que não consigam prever a quantidade de embalagens a serem adquiridas, o que afeta o prazo de entrega, dado que funcionam por pedidos. Portanto, a maioria das empresas considera o setor de Planejamento e Controle da Produção (PCP) a maior dificuldade interna, onde precisa adaptar os tempos de produção, com os tempos de entrega da embalagem, a fim de não deixar estoque parado e nem parar a produção.

A seguinte afirmativa da Cooperativa 2 exemplifica a opinião da maioria sobre o tempo ser a maior especificidade e causadora da incerteza interna de planejamento: "Importa muito, tem que fazer uma programação, a data de entrega tem que ser cumprida, se não entregar atrasa o PCP, atrasa a entrega. Não chega a perder a produção, mas gera um custo interno em alterar o 'mix' de produção para se adaptar aos atrasos".

Essa incerteza interna de planejamento da produção, gerada pela especificidade de tempo, também é afetada pela incerteza externa de volume. Os entrevistados são unânimes em afirmar que a incerteza de volume ocorre, segundo os quais, a ocorrência dessa incerteza se dá mediante a quantidade diferente de pedidos por produtos, com embalagens distintas, que acontecem todos os meses, e pela impossibilidade de acumular muito estoque de embalagem. A incerteza de volume é um dos grandes motivos para que na maioria das empresas não haja contratos formais. Isso porque se fecham contratos atrelados a volume, a empresa poderia ficar com estoque parado de determinado produto ou faltante em outro que dependesse de um fornecedor apenas.

Tal problema não acontece com a Cooperativa 1, por exemplo, pois esta convive com privilégio de ser uma referência única em sua região, portanto, não possui concorrentes de seu porte, por perto. Assim, segundo a cooperativa, os fornecedores o têm como o único cliente relevante da região e o tratam como parceiro, favorecendo sempre os prazos e negociações da Cooperativa 1. Isso ocorre, também, pelo alto investimento da Cooperativa 1 em embalagem, fazendo com que seja um cliente importante para os fornecedores. Portanto, devido à cooperativa buscar diferenciação nas suas embalagens, com certificações e tecnologias distintas, e a relação desta cooperativa com seu fornecedor ser de alto investimento dedicado, de especificidade regional e com uma relação de muita importância para seu fornecedor, considera-se que todas as especificidades na sua transação de embalagem são altas.

Quanto à frequência, para a maioria das empresas existe uma frequência recorrente na compra de embalagem que garante a confiança entre processador e fornecedor. Além de apresentar regularidade na realização de pedidos durante o ano ter um espaço de tempo regular, também são no sentido da recorrência da transação entre fornecedores e processadores. Sendo assim, todos os entrevistados possuem relação de longo prazo com as empresas fornecedoras (de 10 a 15 anos). Conforme ratifica a Cooperativa 1: "A empresa não tem problemas com a negociação, [...], pois está negociando com os mesmos fornecedores há muito tempo, sendo que, com a maior parte estão de 10 a 15 anos".

Quanto às estruturas de governança, a maioria dos processadores tem uma relação de mercado com os fornecedores muito próxima de uma relação contratual. Isso porque não fazem contratos formais com o fornecedor, mas possuem relacionamentos de longo prazo (10 a 15 anos), documentam os registros da negociação como ficha técnica, pedidos, reclamações e devoluções.

Portanto, devido ao que foi citado como a dinâmica da maioria das empresas posicionadas por foco e custos, fora as exceções, tem-se que o fator preço muda constantemente e acaba, também, influenciando na dificuldade da negociação. A afirmativa da Cooperativa 2 ratifica a opinião destas empresas com relação ao fator preço: “Tento brigar na negociação, fazer cotação para comprar do mais barato, troca de fornecedor se subir muito 
o preço".

Por fim, para todos os entrevistados, os atributos da transação que podem determinar uma transação com o fornecedor é a especificidade de tempo de entrega e incerteza de volume, devido à variação da demanda. Além disso, a grande quantidade de problemas de mensuração descritos também deve ser considerada na análise da estrutura de governança. Com isso se encerra a apresentação e análise dos resultados, o que resultam em grande quantidade de informações qualitativas e descritivas a respeito do posicionamento estratégico e da transação que pode ser visualizado no Quadro 4.

Quadro 4 - Síntese das características da transação.

\begin{tabular}{|l|l|l|}
\hline \multicolumn{1}{|c|}{ Posicionamento Estratégico } & \multicolumn{1}{|c|}{ Atributos de transação } & \multicolumn{1}{c|}{$\begin{array}{c}\text { Estrutura de } \\
\text { Governança }\end{array}$} \\
\hline $\begin{array}{l}\text { Diferenciação: mais investimentos } \\
\text { específicos em qualidade, funcionalidade } \\
\text { e marca; }\end{array}$ & $\begin{array}{l}\text { Especificidade: Tempo (Alta), } \\
\text { Física (Alta), Local (Alta), } \\
\text { Investimento (Alta), Humana (Alta); } \\
\text { Frequência: Recorrente; } \\
\text { Incerteza: Volume e Mercado } \\
\text { (Alta), Comportamental (Baixa); }\end{array}$ & $\begin{array}{l}\text { Real: Mercado } \\
\text { (quase híbrida, } \\
\text { denominada de } \\
\text { "parceria") }\end{array}$ \\
\hline $\begin{array}{l}\text { Especificidade: Tempo (Alta), } \\
\text { redução de custos e investimentos/ Buscar } \\
\text { determinado mercado em específico; }\end{array}$ & $\begin{array}{l}\text { Física (Baixa), Local (Baixa), } \\
\text { Investimento (Baixa), Pessoal } \\
\text { (Baixa); } \\
\text { Frequência: Recorrente; } \\
\text { Incerteza: Volume e Mercado } \\
\text { (Alta), Comportamental (Baixa); }\end{array}$ & $\begin{array}{l}\text { Real: Mercado/ } \\
\text { Híbrida }\end{array}$ \\
\hline
\end{tabular}

Fonte: Elaboração do autor.

Senso assim, a partir da análise de conteúdo realizada, as características dos entrevistados foram levantadas e discriminadas no Quadro 4. Além disso, com essa discriminação e com as análises de conteúdo através de roteiros semiestruturados, é possível identificar as estruturas de governança, na compra de embalagem e os posicionamentos estratégicos adotados por cada empresa. Com isso, é possível analisar a estrutura de governança ideal, levando em consideração todos estes fatores.

\subsection{ANÁLISE DA ESTRUTURA DE GOVERNANÇA REAL E IDEAL}

As características influenciadas pelos posicionamentos são: materiais (menos custosos), formas de negociação (cotação, busca pelo menor preço), formas de lidar com o fornecedor (homologar todos e brigar sempre por preço, mudando constantemente de fornecedor), maneiras menos dispendiosas de diferenciar o produto, mensuração menos rigorosa e a busca por preços menores. Tais características diminuem a especificidade de ativo. Consequentemente, diminui a especificidade humana e de investimento dedicado.

A análise geral dos resultados indicou que o posicionamento estratégico predominante entre a maioria dos entrevistados é o de custos e que a estrutura de governança predominante entre os entrevistados é a de mercado. Uma exceção é a Cooperativa 1, que se posiciona por diferenciação. Destaca-se também a exceção da estrutura de governança das Cooperativas 3 e 4, que possuem relação de contratos. Em uma análise mais detalhada, tem-se que a especificidade de ativo é considerada como variável chave desta relação entre o posicionamento estratégico e a estrutura de governança da compra de embalagem na indústria avícola, isto porque a Cooperativa 1, que realiza estratégia de posicionamento por diferenciação, utiliza-se de produtos mais complexos e investimentos dedicados mais altos. 
Esta complexidade em seus produtos fazem com que a empresa tenha como objetivo realizar mais investimentos específicos em qualidade, funcionalidade e marca, a fim de assegurar o retorno de seus investimentos específicos, conforme previsto pela ECT. Sendo assim, o estudo apresenta que a empresa cuja embalagem contém mais investimentos específicos é a que se posiciona por diferenciação, conforme previsto por Williamson (1985) e Saes (2009).

Quanto à especificidade, tem-se que as especificidades físicas e locacionais do produto são baixas, segundo a maioria dos entrevistados, principalmente para os posicionados por custos, pois não há investimento específico e nem necessidade de proximidade do fornecedor para essas organizações. A exceção é para o entrevistado posicionado por diferenciação, pois a especificidade física, locacional, de pessoal e de investimento dedicado do ativo é alta.

Já a especificidade temporal é identificada como alta em todos os posicionamentos, mais fortemente quando a empresa é posicionada por custos, pois troca de fornecedor rapidamente, e o não cumprimento dos prazos de entrega de embalagens gera ruptura na entrega. Conforme Williamson (1991), a especificidade de tempo influi diretamente na qualidade, planejamento e custos, por isso geram problemas pré e pós-contratuais. Segundo os dados apresentados, a maioria dos entrevistados acorda informalmente o tempo de entrega. Isso faz com que muitos problemas pós-contratuais sejam gerados. Os problemas derivados do atraso da entrega de embalagem é a falta de embalagem no estoque, acentuando a incerteza de volume, conforme identificaram Crook et al. (2013), gerando, como consequência: perda de valor da carne de ave (por precisar utilizar uma embalagem de menor valor agregado para entregar o produto); atrapalhar o planejamento da produção; parar a produção e processamento; atrasar a entrega do produto aos distribuidores.

Já com relação ao atributo incerteza, tem-se que a incerteza de volume e de preço ocorre com mais frequência do que a comportamental. Segundo Williamson (1991), mediante incertezas ambientais há uma tendência de a estrutura ser mais verticalizada e, segundo Crook et al. (2013), mediante incerteza de volume há uma tendência de a estrutura ser de contratos.Para os autores, a incerteza de volume se dá pela variação de demanda. As informações levantadas no estudo confirmam a teoria, nesse caso, pois a ocorrência dessa incerteza se dá mediante a constatação da entrega de quantidade diferente de pedidos por produtos, com embalagens distintas, que acontecem todos os meses, e pela impossibilidade de acumular muito estoque de embalagem.

Quanto à frequência, tem-se que, mediante as incertezas, as especificidades e alta variabilidade em muitas dimensões mensuráveis existem uma frequência recorrente, na compra de embalagem, o que é importante, pois gera maior reputação e certa confiança entre processador e fornecedor, conforme Williamson (1991). Tais fatores analisados contribuem para a decisão de manter uma estrutura de governança voltada para o mercado ou para uma forma contratual informal nas empresas e cooperativas entrevistadas.

No entanto, contrariando o senso comum presente entre os entrevistados, identificouse que há sim inadequação das estruturas de governança, pois a maioria dos entrevistados possui custos de transação altos, devido a suas especificidades e incerteza de volume serem altas, causando ineficiência da transação. Identifica-se, assim, inadequação à estrutura de governança, pois contraria a teoria preconizada por Williamson (1991), conforme Quadro 5.

Quadro 5 - Estrutura de governança ideal para o Posicionamento Estratégico

\begin{tabular}{|c|c|}
\hline Posicionamento Estratégico: & Estrutura de Governança ideal, segundo a ECT e ECM: \\
\hline DIFERENCIAÇÃO & Híbrida (com contratos formais, próxima à hierárquica) \\
\hline CUSTOS/FOCO & Híbrida (próxima a mercado, com contratos informais) \\
\hline
\end{tabular}

Fonte: Elaboração dos autores. 
Sendo assim, conforme o Quadro 5, parte da inadequação da estrutura se dá pela necessidade de manter o padrão competitivo e, portanto, pela estratégia competitiva das empresas. Adicionalmente, segundo os dados levantados, é possível observar que o posicionamento estratégico influencia na escolha da estrutura de governança, assim como o tamanho da empresa, a variedade de produtos e estratégias de eficiência na transação.

Portanto, tem-se que a estrutura ideal para empresas e cooperativas é a híbrida (com contratos formais e informais), devido aos fatores inerentes ao posicionamento, que levam a altas especificidades e incerteza de volume nas transações. A incerteza, neste caso, leva a uma conclusão diferente do que foi previsto por Zylbersztajn (2018), justamente por ser uma incerteza de volume, que se adequa aos pressupostos de Crook et al. (2013).

\section{CONSIDERAÇÕES FINAIS}

Com este estudo, é possível compreender como a busca de eficiência na transação com o segmento fornecedor de embalagem é influenciada pelo posicionamento estratégico do segmento processador no SAG de frango de corte no Paraná. O primeiro resultado foi identificar que o posicionamento estratégico de liderança em custos foi identificado como predominante entre os entrevistados, embora a diferenciação também esteja presente.

Um segundo resultado da pesquisa foi identificar e caracterizar os atributos de transações nas relações envolvendo o segmento fornecedor de embalagens e o segmento processador e a estrutura de governança presente. De acordo com os resultados da pesquisa, a forma de estrutura de governança real, ou seja, que é predominante na realidade da transação entre processador do SAG de frango de corte e fornecedor de embalagem, é a forma denominada de mercado. A análise final demonstra, entretanto, que a estrutura híbrida seria mais adequada.

Por fim, o terceiro resultado da pesquisa foi analisar como a estrutura de governança sofre influência do posicionamento estratégico. De acordo com a análise, tem-se que o posicionamento de diferenciação aumenta a especificidade de ativos; já o posicionamento por custos e foco é o efeito oposto.

Portanto, conclui-se que o posicionamento estratégico dos processadores no SAG de frango de corte do Paraná influencia na estrutura de governança, através do impacto que essas estratégias geram na especificidade do ativo, principalmente. Sendo assim, as principais contribuições deste estudo são a respeito da compreensão da transação intersetorial, entre a indústria avícola e a indústria de embalagem, e como essa relação tem participação na forma de manter a competitividade e eficiência do sistema de frango de corte, resolvendo "gargalos estratégicos". 


\section{REFERÊNCIAS}

ASMUSSEN, C.G.; FOSS, K.; FOSS, N.J.; KLEIN, P.G. Economizing And Strategizing: How Coalitions And Transaction Costs Shape Value Creation And Appropriation. Strat Mgmt J. Accepted Author Manuscript, 2020.

ASSOCIAÇÃO BRASILEIRA DE EMBALAGEM (ABRE). Estudo macroeconômico da embalagem ABRE/ FGV - 2018: Dados de mercado. Disponível em: http://www.abre.org.br/setor/dados-de-mercado/dados-de-mercado/. Acesso em: 4 out. 2018.

ASSOCIAÇÃO BRASILEIRA DE PROTEÍNA ANIMAL (ABPA). Relatório anual de 2017. Disponível em:http://abpa-br.com.br/setores/avicultura/publicacoes/relatoriosanuais/2017. Acesso em: 9 maio 2018.

ASSOCIAÇÃO BRASILEIRA DE PROTEÍNA ANIMAL (ABPA). Relatório anual de 2018. Disponível em: http://abpa-br.com.br/setores/avicultura/publicacoes/relatoriosanuais/2018. Acesso em: 25 set.2018.

AUGUSTO, C. A., et al. Pesquisa Qualitativa: rigor metodológico no tratamento da teoria dos custos de transação em artigos apresentados nos congressos da Sober (2007-2011). Revista de Economia e Sociologia Rural, v. 51, n. 4, p. 745-764, 2013.

AUGUSTO, C.A.; SOUZA, J. P.; CARIO, S. A. F. Integração vertical em montadoras automotivas. RAC, v. 22, n. 5, p. 704-725, 2018.

AUGUSTO, C.A.; SOUZA, J. P.; CARIO, S. A. F. Custos de transação no setor automotivo: atributos transacionais, pressupostos comportamentais e limitações teóricas. Rev. Iberoam. Estratég. São Paulo v.18 n.2, pp. 238-263, 2019.

ARAÚJO, G. C.; BUENO, M. P.; BUENO, V. P.; SPROESSER, R. L.; SOUZA, I. F. Cadeia produtiva da avicultura de corte: avaliação da apropriação de valor bruto nas transações econômicas dos agentes envolvidos. Gestão \& Regionalidade, v. 24, n. 72, p. 6-16, set./dez., 2008.

BARDIN, L. Análise de conteúdo. São Paulo, Brazil: Edições 70, 2016.

BARÃO, M. Z. SBRT - SERVIÇO BRASILEIRO DE RESPOSTAS TÉCNICAS (Dossiê Técnico): Embalagens para produtos alimentícios. Instituto de Tecnologia do Paraná TECPAR, 2011.

BASSANELLO, C. S.; DE SOUZA, J. P. Influência do setor de embalagens no SAG de leite: o olhar do segmento distribuidor. Gestão e Desenvolvimento em Revista, v. 4, n. 2, p. 133 $148,2019$.

BASSI, N. S. S.; SILVA, C. L.; SANTOYO, A. Inovação, pesquisa e desenvolvimento na agroindústria avícola brasileira. Estud. Soc. e Agric., Rio de Janeiro, v. 21, n. 2, p. 392-417, 2013. 
CALEMAN, S. M. Q.; ZYLBERSZTAJN, D.; PEREIRA, M. W. G. ; OLIVEIRA, G. M. Organizational tolerance in agro-industrial systems: an empirical application for the meat sector. Revista de Administração (FEA-USP), v. 52, p. 456-466, 2017.

CROOK, T. R.; COMBS, J. G.; KETCHEN JR, D. J.; AGUINIS, H. Organizing around Transaction Costs: What have we learned and where do we go from here? Academy of Management Perspectives, v.27, n.1, p.63-79, 2013.

CUNHA, C. F., SAES, M. S. M. \& MAINVILLE, D.Y. Custos de transação e mensuração na escolha da estrutura de governança entre supermercados e produtores agrícolas convencionais e orgânicos no Brasil e nos EUA. Gestão e Produção, v. 22, n. 1, p. 67-81, 2015.

EMBRAPA - EMPRESA BRASILEIRA DE PESQUISA AGROPECUÁRIA MINISTÉRIO DA AGRICULTURA, PECUÁRIA E ABASTECIMENTO. Macrologística da produção agropecuária de 2016. Disponível em: https://www.embrapa.br/macrologistica/producao-agropecuaria. Acesso em: 10 jun. 2018.

FARINA, E. M. M. Q. Competitividade e coordenação de sistemas agroindustriais: um ensaio conceitual. Gestão \& Produção, v. 6, n. 3, p. 147-16, 1999.

FOSS, K.; FOSS, N. J. The next step in the evolution of the RBV: integration with transaction cost economics. Copenhagen Business School. Working Paper, March, 2004.

INSTITUTO BRASILEIRO DE GEOGRAFIA E ESTATÍSTICA- IBGE. Pesquisa Trimestral de Abate de Animais 2017. Disponível em: http://www.ibge.gov.br. Acesso em: 10 abr. 2018.

JANK, M. S, FARINA, E. M. Q. GALAN, V. B. O agribusiness do leite no Brasil. São Paulo: Milkbizz, 1999.

KETOKIVI, M., MAHONEY, J. T. Transaction cost economics as a theory of supply chain efficiency. Production and Operations Management, 29(4), 1011-1031, 2020.

MONTEIRO, G. F. A.; ZYLBERSZTAJN D. Direitos de propriedade, custos de transação e concorrência: o modelo de Barzel. EALR, Brasília, V. 2, n. 1, p. 95-114, jan./jun. 2011.

MUGWAGWA I.; BIJMAN J.; TRIENEKENS J. Typology of contract farming arrangements: a transaction cost perspective, Agrekon, 59:2, 169-187, 2020.

NASCIMENTO, L.; STEINBRUCH, F. "The interviews were transcribed", but how? Reflections on management research", RAUSP Management Journal, Vol. 54 N. 4, pp. 413 429, 2019.

PORTER, M. Competitive strategy: techniques for analyzing industries and competitors. New York: Free Press, 1980.

RAIMUNDO, L. M. B.; BATALHA, M.O. Mercado de carne suína na cidade de São Paulo: segmentos e estratégias. Gestão \& Produção, v.22, n.2, p.391-403, 2015.

SAES, M. S. M. Estratégias de diferenciação e apropriação da quase renda na agricultura: a produção de pequena escala. São Paulo: Annablume, Papesp, 2009. 
SKARBEK, D. Qualitative research methods for institutional analysis. Journal of Institutional Economics, 1-14, 2020.

YUAN Y.; CHU Z.; LAI F.; WU H. The impact of transaction attributes on logistics outsourcing success: A moderated mediation model, International Journal of Production Economics, Volume 219, Pages 54-65, 2020

WAKER, R, NÄ̈̈S, I., Structural Attributes Dynamics of the Brazilian Broiler Production Chain. Braz. J. Poult. Sci., v.20, n.3, p.517-526, sep., 2018.

WILLIAMSON, O. E. (1991) Comparative Economic Organization: The Analysis of Discrete Structural Alternatives. Administrative Science Quarterly, Thousand Oaks, v.36, p. 269296.

ZYLBERSZTAJN, D. Conceito geral, evolução e apresentação dos sistemas agroindustrial. In: ZYLBERSZTAJN, D.; NEVES, M. F. (Org.). Economia e gestão de negócios agroalimentares. São Paulo: Pioneira. p. 1-21, 2000.

ZYLBERSZTAJN, D. CALEMAN, S. M. Q. Organizational tolerance: explaining diversity of complex institutional arrngements. In: Julian Briz; Isabel de Felipe. (Org.). Las Redes de Cadenas de Valor Alimentarias en el Siglo XXI. 1 ed. Madrid: Editorial Agrícola Española S.A., 2012, v. 1, p. 157-174.

ZYLBERSZTAJN, D. Measurement costs and governance: bridging perspectives of transaction cost economics. Caderno de Administração, v. 26, n. 1, 2018. 